\title{
Using Activity Theory to Review Internet Technology Engagement by Real Estate Negotiator in Malaysia towards Agency Best Practice
}

\author{
Azir Rezha bin Norizan ${ }^{1 *}$, Ahmad Naim Che Pee ${ }^{2}$ \\ ${ }^{1}$ Malaysian Institute of Information Technology, Universiti Kuala Lumpur, Kuala Lumpur, Malaysia \\ ${ }^{2}$ Faculty of Information and Communication Technology, Universiti Teknikal Malaysia Melaka, Melaka, Malaysia \\ Received: $15 / 07 / 2020$ \\ Accepted: $13 / 09 / 2020$ \\ Published: $10 / 10 / 2020$
}

\begin{abstract}
Real estate is a revelatory industry for the study of ICT uses because it is information-intensive and realtors are information intermediaries between buyers and sellers. As agents, buyers and sellers increase their uses of ICT, they also change how they approach their daily work. Information intensive industries, by their nature, show the greatest impacts due to ICTs that enable information sharing and the bypassing of traditional information intermediaries. However, while the effects and uses of ICT are often associated with organizations (and industries), their use occurs at the individual level. In other words, it is changes to individual work related to the use of ICTs that reshape both organization and industry structures, and vice-versa. In this study, we use activity theory to provide an analytic perspective within the setting in Malaysia. Data reveal historical structures of this industry guiding the day-to-day work of agents, buyers, sellers and the role of agency. Many of these structures are embodied in a set of explicit contracts that reify existing structures and legitimize realtors' actions. While looking from the agencies practices, we explain possible improvement in the real estate industry following the advancement of internet \& mobile technology, viewing the possibilities towards the use of IOT in real estate industry.
\end{abstract}

Keywords: ICT, Real Estate, IOT, agency, digital media

\section{Introduction}

The internet and mobile telephone have enabled vast improvement in technology platforms applied to nearly all areas of our lives. This has happened through the facilitation of three different activities which are information provision; transactions; and management and control. Wikipedia and on-line newspapers are examples of on-line information engines. Initially, the internet, mobile telephony, social networking and e-mail were all about information, hence the previously ubiquitous use of the term 'infotech'[7]. Information is the key input into the due diligence phase of a transaction. Shopping on-line was therefore the natural next phase of technology development. Paypal, Amazon and on-line banking are examples of internet and mobile telephony being used as a medium for the exchange of money, goods and services. PCs, tablets and mobile phones are potential dashboards for controlling electronic functions [10]. The Internet of Things (IoT) allows objects to be measured (information provision) but also sensed and/or controlled remotely across the existing network infrastructure, creating opportunities to adjust or turn systems on or off remotely [6]. As an example, Google's 2014 acquisition of Nest to create a Google IoT division was seen at the time as a significant moment. Also, the remote control of driverless cars and delivery vehicles, plus bots offering a range of services, are setting in motion many thought processes imagineering the likely future of logistics and retail real estate [1].

Real estate is the largest asset type and one of the last to adopt technological change and the innovation that tech can bring [13]. This should present a massive area of opportunity for entrepreneurs. The opportunity is driven not only by the size of the industry and its lack of tech adoption, but also by industry practices plagued by inefficient processes and unnecessary transactional costs defended by self-interested professionals and institutions.

The real estate business helps fulfil one of our most basic needs: shelter. For many people, this shelter is a house, but real estate is more than just shelter and houses. It includes apartments, condominiums, cooperatives, farms, retail stores, office buildings, shopping centres, warehouses, industrial plants, medical centres, and many other types of property. Hundreds of thousands of licensed professionals sell, lease, manage, appraise, or otherwise work full time in the real estate industry [10]. The industry also provides employment for many part-time and support personnel.

Real estate is not known as an industry which readily embraces change [5]. The nature of the asset class, which comprises large

*Corresponding author: Azir Rezha bin Norizan, Malaysian Institute of Information Technology, Universiti Kuala Lumpur, Kuala Lumpur, Malaysia. E-mail: azir@unikl.edu.my 
heterogeneous assets traded in a largely private market, is perhaps a good reason for this. Homes may be too important a part of a private portfolio to take any risks with the process whereby it is traded, held or valued. It may also be the case that there is an agency problem: the professional advisers that dominate the transaction process clearly have an interest in protecting their income sources, so chartered surveyors, brokers and lawyers might all be expected to resist tech-driven innovations designed to 'disrupt' their work. Nevertheless, in current times we are witnessing a battle for market share between traditional advisers and a discernible second wave of technology-based innovation [2].

Previous study saw that the growth of ICT in one industry allows for removal of information intermediaries which including the real estate agents [11]. Analysis of the data from a structurational perspective suggests that real estate agents have lost some of the domination originally created by their control over the information resources. But the changes that happen in industry structure is much more complex than simple disintermediation. The real estate agent's actions are helping them to restructure their roles in the industry which we going to discuss in the next section.

\section{Real Estate Industry in Malaysia}

Since Malaysia gained independence in 1957, the real estate industry has grown rapidly. Evidence shows that real estate is one of the main drivers of Malaysian economic growth and the engine of social stability thus an important part of economic development. The growth of the real estate industry is closely related to developments in other industries as well such as in the corporate and commercial sector, hospitality and tourism sector, retail sector, information technology (IT) sector, infrastructure, service sector and many other fields [2]. However, there are some challenges that exist today that are a major contributor to the imbalance between socio-economic achievement and real estate deals. According to a study conducted from 2002 to 2016, the level of inability to buy a home has increased drastically. The level of property ownership has dropped from 2012 to 2014. The price of home offered to the market is increasing and at the same time affecting the level of property ownership among the general public [9].

On the economic basis, when demand equals supply, then market equilibrium will occur. However, this does not seem to exist in the real estate market - especially in urban areas. In major cities in Malaysia, housing supply is more geared towards highcost housing such as bungalows, apartment and residential services. For example, in Pulau Pinang alone, all properties launched in 2016 are worth more than RM250,000 and most are worth RM500,000 to RM1,000,000. Home transactions under RM500,000 also dropped to $83 \%$ in the third quarter of 2014 compared to $98 \%$ in 2002 [9].

The lack of data and statistics has created a huge gap in the analysis of demand and housing. This needs to be addressed so that comprehensive and holistic analysis can be carried out to enable more effective monitoring and planning into these challenges [10]. One of the key issues regarding data and statistics at the state and central levels is the incomplete and up to date database. In addition, most data do not meet the spatial scale and data is only written and not digital.

The real estate business has now become one of the highest paying salary in Malaysia. This opportunity has been grab by huge number of people regardless of their gender, age or experience level [10]. We choose to locate our study in Selangor State area as more than 500 real estate agencies located within. We use close observation and unstructured interviews as the methods to collect information of 267 real estate negotiator from 14 different agencies. The respondents were from three major Malaysian races, $72 \%$ malay, $16 \%$ chinese and $12 \%$ indian. In terms of age, range of respondents were aged between 30-40 years. These respondents were selected while taking into account the level of literacy towards internet and smart phone technology. The study looked at the real estate business activities, therefore the respondents were among real estate negotiator (REN) because REN play a very significant role in the activity. The selected REN also has more than 3 years of work experience and can be considered skilled in real estate activities.

\section{Activities of Real Estate Negotiator}

Due to fast technological development, studies of digitalisation and platforms have explored more in the past decade, but none has gone detail into micro level of activities in the real estate industry. We use activity theory (AT) framework to help in looking further detail action and interception that occur in the stakeholder's activities [3].

Activity theory is an analytical framework that has the ability to examine phenomena in their native context through multiple perspectives and can be used for analysis of qualitative data. AT aims to connect the individuals and their surrounding social structures by pursuing a monist approach in which both are studied at the same time by focusing on the generated activity [8]. The framework has the ability to look further than design and social innovation as an isolated method, process or idea by also providing insight into the ecosystem in which an initiative takes place and to which it is inextricably linked [3][12].

The relationship between subject, tools and object can be considered as an activity conducted by a subject to achieve a certain outcome [11]. Collective activities are driven by communal motives, which are formed when collective needs might potentially be fulfilled by certain objects. Linking the subject-tools-object relationship to the wider social context are rules, which can be implicit or explicit, the broader community, consisting of other activity systems and, if applicable, shared and coordinated by a division of labour [11]. Activity system is the basic unit of analysis in AT which are the relationship between these different elements.

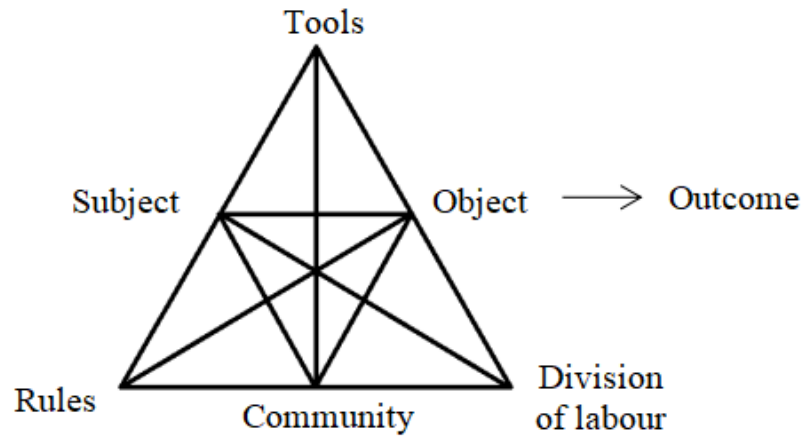

Figure.1: Activity System (Engeström, 1999)

As the study looked at qualitative information, in-depth 
observation and open-ended interviews were conducted on 267 real estate agents and involved 14 real estate agencies around the Klang Valley, Malaysia. By putting the Real Estate Negotiator (REN) as the subject; and properties for sale as objects to activities, Observation of activity was done by looking at the elements or entities that surround the subject and object to be matched with other entities such as those on figure 1 .

A real estate negotiator needs to be registered with The Board of Valuers, Appraisers and Estate Agents Malaysia (BOVAEA) through any Real Estate Agency. The existence of BOVAEA helps in controlling the operation property businesses by setting a rules for approving a sale. Real estate agency is a company operated by Real Estate Agent (REA) and depending on the size of the agency, an agency can have up to 500 registered RENs. REN works under REA supervision and paid according to the case of the sale of the property and the percentage of commission earned varies according to the agreement made by the agency.

Property selling activity begins with the interaction between REN and the owner who looking to sell the property. Owner must enter into an agreement to allow the REN to act as a representative to sell his property. There are two types of agreement; exclusive appointment where only the REN appointed is entitled to deal with the sale of the property; and open appointment in which REN shares the rights with other RENs appointed to carry out the sale. Before making an agreement, usually the REN will conduct a review of the quality and condition of the home to suggest repairs to be made by the owner in order to set a reasonable price.

After the agreement, REN will start their advertising work to reach potential buyers with the various methods they know. REN also need to get the average value of the property to be advertised from the valuer. There are some agencies that have their own valuer to facilitate REN's work, but for agencies that don't provide valuers, REN needs to get valuer services from other companies. This is because the market value of the advertised property must be accurate, otherwise REN and agencies may be subject to legal action by BOVAEA. After getting serious buyer, REN will conduct a buy-in review of the buyer's financial eligibility, whether he is eligible to purchase the property. If eligible, REN will bring buyers to view properties and continue further discussions until the buyer agrees to purchase and sign the agreement document.

Next, the REN will need to bring the property sale agreement from both the owner and buyer to the agency's verification. Agency approval is required because the agency is the real intermediary between the owner and buyer in the property sales activity, while REN represents the agency. The next process is assisting the buyer to apply property's loan from bank, and at the same time helping the owner and buyer in dealing with the appointed lawyer until the buyer successfully obtain the bank loan.

There are also situations where RENs need to cooperate with other RENs from the same or different agencies, to get a case of property sales. In such cases, the value of the commission will be divided according to the previously agreed agreement prior to cooperation. Overall activity can be illustrated by Figure 2. Based on figure 2, we can see more clearly the relationship between the entities involved in the activity. However, selling a property is just one of REN's activities in the real estate field of work. A newly enrolled REN will usually be paired with a senior REN to learn the routine that needs to be done. Senior REN in this study is a person who has completed all training sessions provided by the agency, and already have a lot of property listings and has a high frequency of sales cases. The basic activities REN has to do is promoting their identity as a real estate negotiator; and compiling a list of properties for sale as well as obtaining the rights as official dealers. Only then will REN act to find potential buyers as described.

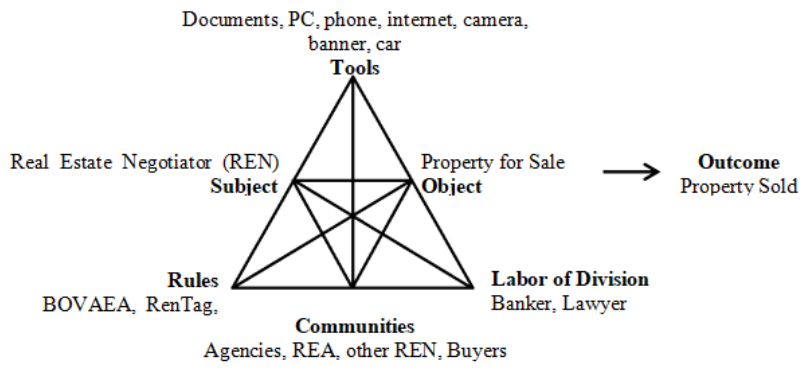

Figure 2: Activity System of a REN to sale a property

The real estate industry can also be seen as a multilevel concept business starting with REA as a top leader. REA as an agency will recruit REN to assist in real estate negotiation work and deal directly with both the seller and the buyer. REN will receive a percentage of the commission based on the agreement with the agency. Senior RENs will usually look for new REN prospects as a down-line and can earn commissions from their down-lines, indirectly become one of REN activities.

\section{Internet Engagement in Ren Activity}

By observing the activities in the real estate industries surrounding REN and the agencies, the use of technology especially smartphones and internet seems compulsory these days. Looking for property to buy or to sale has becoming lots easier as how buying and selling things online has become common. There are just a lot of platforms ready to be use for the property owner to market their property, and the REN will get their attention from those platforms to get appointed.

Open interviews that has been done among 267 REN allow us to analyse some interesting data regarding their activities. The activity of a REN usually involves marketing work, whether to market their identities and professions as real estate consultants, or market the property for which they are an authorized seller. As many as $92 \%$ of respondents who are all senior REN, states have established their own platforms whether professional website, or a large network of social media followers. The rest say they have no skills in developing their own website and rely solely on social media in search of property or potential buyer. The majority agree that the existence of their own official website helps to enhance the professional perception of their careers indirectly increasing the success rate of being appointed as the official seller for a property.

Variety of smartphones apps or websites available for the owner to do marketing on their own. Even social media networks such as Facebook and instagram could do such work as almost everyone has their own accounts. Selling and buying a properties are not the same as selling and buying a car because of the detail procedures, involving huge amount of money and taking lots of time. Common people usually aren't ready and do not understand the work need to be done before the property could change the owner, and most people don't want to waste their precious time 
in handling the documentations and procedure. Therefore REN always get the opportunity to help by getting appointed as official seller.

REN also has accumulated a list of potential buyers from other sold properties activities. Since REN working for the agency, REN has access to the facilities provided by the agency. The agency acts to facilitate the work of documentation, which should be done by REN. A good agency should always support the activities of the REN and will indirectly help increase agency productivity.

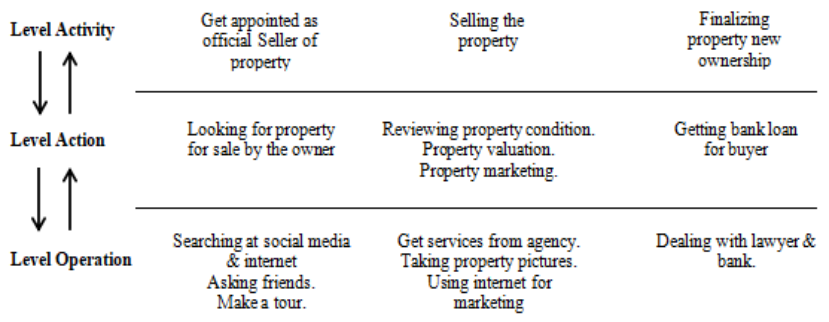

Figure.3: Activity Hierarchy Structure of a REN to sale a property

Based on our observations of 14 real estate agencies in the Klang Valley, only 3 agencies provide platforms such as official websites and social media pages with the aim of helping them grow their REN market. Only one agency has undertaken the initiative by using an online documentation system. The agency uses a web-based system where REN and other stakeholders simply need to enter the required input into the system online, will then be processed by the agency. The advances in internet technology have made it possible for all the dealings to be done online with the use of mobile devices.

However, the majority of agencies still do not want to invest in the use of internet technology. This is due to the level of awareness of the importance of implementing the latest technology in the industry and most agencies feel that more investment is needed for other matters such as courses and training. Another agency used video streaming technology as a delivery method for training sessions and courses. Newly registered RENs, or potential RENs will be given keywords to access training materials from the agency's website, and will only need to attend lectures by the agency through video streaming methods. The agency stated that this method facilitates the new or prospective REN to obtain the necessary information without having to physically attend the agency's office, and accessible from anywhere.

All respondents agree that by using internet banking, money transfer is easier and faster. Money transfers are often made in matters involving REN whether payments are made by REN to the agency, payment by agency to REN, and payment by the owner to REN. However, the documentation involving the bankers and lawyers still have to follow the existing method as it is beyond the control of the agency.

The agency also uses the official portal as a hub to compile a list of properties for sale by each REN registered under the agency. In addition to making it easier to find the property wanted by the potential buyer, this centralized method also raise the probability to get the property being sold. This is because when each REN uses the agency's official portal to market the property, this activity will also market the official portal. If the buyer does not find the desired property, the portal also provides a segment for potential buyers to input their desired property criteria. When any REN from the agency uploads a new property for sale, which meets the criteria set by the potential buyer, the system will send the notification in the form of an email or SMS to the buyer

Table 1: The way respondent's agency integrating internet into REN activity

\begin{tabular}{|c|l|}
\hline Agencies & \multicolumn{1}{|c|}{ The use of Internet } \\
\hline \multirow{4}{*}{ A } & - Market RENs property listings. \\
\cline { 2 - 3 } & - Online property viewing by using images \& videos \\
\cline { 2 - 3 } & - Fill up online form for documentation \\
\cline { 2 - 2 } & - Services payment gateway \\
\hline \multirow{3}{*}{ B } & - Video based training course. \\
\cline { 2 - 2 } & - Online property valuation. \\
\hline \multirow{2}{*}{} & \\
\hline C & - REN progress monitoring system. \\
\hline
\end{tabular}

Another use of internet technology in the REN activity that we notice from our observation is property evaluation process. The conventional method is that REN should come to the agency's office for evaluation services. The websites provided by one of the agencies also provide an online valuation service to enable REN to check the average value of the property. The website requires a password to access the database that has the current value of the property.

\section{Room for IOT Enhancement in Real Estate Industry}

Internet of Things refers to an infrastructure of technology where devices, such as lighting systems, thermostats, electrical outlets, and plumbing are connected via the Internet and coordinate to perform "smart" functions. There's no doubt that IoT is improving consumers' lives, but it's also having a profound impact on the real estate industry. IoT is already having a significant impact on the real estate industry, helping companies to focus on cost reduction and overcome dwindling profit margins and fierce competition [4]. The ecosystem of connected world is designed to gather data and gain meaningful insights, enabling real estate and construction firms to improve speed of operations and streamline efficiency and thus reducing construction cost and improving bottom lines.

IoT devices provide actionable and valuable property insights that real estate agents can leverage to improve sales. Agents can provide this information to prospective buyers to increase confidence. Buyers can use accessible, informed analytics to make quick decisions. It able to provides lenders and investors with an in-depth analysis of homes before they make actually make a purchase. Prospective buyers have information to understand home evaluations [5].

Beacon technology is another use of IoT in the real estate market. Beacons are Bluetooth devices that can be placed anywhere to transmit information via the Internet. From square footage and price to photos and 360-degree virtual tours, beacons deliver all the essential details of a home to prospective buyers' phones. For example, BeaconSAGE enables prospective clients to begin viewing a property before the agent arrives. When a potential buyer comes within the radius of a beacon, their phone 
picks up the beacon's signal and the beacon provides the client with the link to begin viewing the property. Agents can also use beacon technology to provide clients with a personalized buying experience, showing them only the information they want to see.

It's clear that IoT applications in real estate will change the industry and also our lives in numerous ways. With all of this predictive technology, buying, owning, and selling your home is becoming more accessible than ever. Not only can IoT help homeowners become more aware of their home's functionalities; it can also generate more market value for your home [13].

The practical utilization of this technology just began and requires further development. At the moment, the acquisition costs for smart home or office solutions are still relatively high. With the further expansion of the technology, however, economies of scale will take gain. Hence, the next few years the Internet of Things can gradually be integrated into our everyday lives across the board

\section{Conclusions}

This paper has shown how activity theory can potentially be an effective analytical framework for design and social innovation initiatives through its ability to study as they occur in their own context, revealing what motivates the stakeholders, how they achieve their goals, and how they were influenced by the environment. The study also looks at the potential of technological advancements in real estate activities especially the adoption of IoT. In addition to the use of IoT written in this paper, a lots higher level trends that provide a kind of blueprint for the near future of real estate industry such as the block-chain, virtual walkthroughs, machine learning and ROI calculation. But it's hard to predict exactly how new technologies will develop and how exactly they'll change the real estate industry.

As the industry moves into the digital age, innovative resources and platforms are emerging all of the time to help property buyers and sellers alike. The key will be encouraging the adoption of these new technologies so that all stakeholders can benefit from more accurate information, and ultimately, make more informed, lucrative decisions. Given the consumer demand for more technology in the real estate industry, we're likely to see more agents and brokerages investing in high tech to stay competitive in the market

\section{Aknowledgment}

Journal editorial doard thanks following reviewers to review this article.

\section{Ethical issue}

Authors are aware of, and comply with, best practice in publication ethics specifically with regard to authorship (avoidance of guest authorship), dual submission, manipulation of figures, competing interests and compliance with policies on research ethics. Authors adhere to publication requirements that submitted work is original and has not been published elsewhere in any language.

\section{Competing interests}

The authors declare that there is no conflict of interest that would prejudice the impartiality of this scientific work.

\section{Authors' contribution}

All authors of this study have a complete contribution for data collection, data analyses and manuscript writing.

\section{References}

1 Abera T, Asokan N, Davi L, Koushanfar F, Paverd A, Sadeghi AR, Tsudik G. Things, trouble, trust: on building trust in IoT systems. InProceedings of the 53rd Annual Design Automation Conference 2016 Jun 5 (pp. 1-6)

2 Aggarwal, S. To Boost Growth And Transparency In Indian Real Estate Sector! REITs 2014 August 28. Retrieved from http://www.mondaq.com/india/x/336834/FundManagement REITs/REITs To Boost Growth And Transparency In Indian Real Estate Sector

3 Azir Rezha N, Maksom Z, Naim CP. Tackling design issues on elderly smartphone interface design using activity centered design approach. ARPN J. Eng. Appl. Sci. 2014;9(8):1190-6.

4 Baran P, Baum R, Bieńkowski J, Golec A, Korzeniewski J, Kuźmar S, Lapniewska Z, Lewandowska-Gwarda K, Markowicz I, Miklaszewska A. The Role of Technology in Supporting Communication for Real Estate Agents-Evaluation of the Phenomenon. Acta Universitatis Lodziensis. 2019;341:2.

5 Dahl J, Lingius Cerda B. Assessing Performance Gains of a P2P System Based on User Acceptance: A Case Study on National RealEstate Companies.

6 Du D, Li A, Zhang L. Survey on the applications of big data in Chinese real estate enterprise. Procedia Computer Science. 2014 Jan 1;30:24-33.

7 Dunning R, Levy D, Watkins C, Young G. Technological change and estate agents' practices in the changing nature of housing transactions. Housing Studies. 2019 May 28;34(5):849-67.

8 Engeström Y. Expansive visibilization of work: An activitytheoretical perspective. Computer Supported Cooperative Work (CSCW). 1999 Mar 1;8(1-2):63-93.

9 Guide, G. P. Property in Malaysia| Malaysian Real Estate Investment. 2019.

10 Ibiyemi A, Ogungbemi O, Awodiran R. Regulation of Real Estate Agency Practice in Malaysia: An Investigation for Nigeria International Journal of Humanities Social Sciences and Education. 2014;1(10):65-76.

11 Tan S, Melles G. An activity theory focused case study of graphic designers' tool-mediated activities during the conceptual design phase. Design Studies. 2010 Sep 1;31(5):461-78.

12 Tjahja C, Yee J, Aftab M. Objects of Design: Activity Theory as an analytical framework for Design and Social Innovation. InConference Proceedings of the Design Management Academy 2017 Jun 7 (Vol. 3, pp. 931-947). Design Management Academy.

13 Vuong H, Tonenchuk V, Orlovskis E, Stoyanov I, Mendes R, Ramon J, Linares M. New Technology and Data in Real Estate Education. European Real Estate Society (ERES); 2019 Jan 1. 